\title{
Neutralizing antibody: a savior in the Covid-19 disease
}

\author{
Sneh Lata Gupta ${ }^{1} \cdot$ Rishi Kumar Jaiswal ${ }^{2}$ (D)
}

Received: 13 October 2021 / Accepted: 24 November 2021 / Published online: 6 January 2022

This is a U.S. government work and not under copyright protection in the U.S.; foreign copyright protection may apply 2021

\begin{abstract}
Coronavirus outbreak was declared a pandemic by World Health Organization (WHO) in March 2020. The pandemic has led to a devastating loss of life. It has shown us how infectious diseases can cause human existence at stake, and community health is important. The spike protein is the most immunogenic component of the virus. Most vaccine development strategies have focused on the receptor-binding domain (RBD) in the spike protein because it is the most specific target site that recognizes and interacts with human lung cells. Neutralizing antibodies are generated by the humoral immune system and reduce the viral load by binding to spike protein components. Neutralizing antibodies are the proteins secreted by plasma cells and serve as an important part of the defense mechanism. In the recent Covid-19 infection, neutralizing antibodies can be utilized for both diagnostic such as immune surveillance and therapeutic tools such as plasma therapy. So far, many monoclonal antibodies are in the clinical trial phase, and few of them are already in use. In this review, we have discussed details about neutralizing antibodies and their role in combating Covid-19 disease.
\end{abstract}

Keywords Receptor-binding domain (RBD) · Covid-19 · Neutralizing antibody · Angiotensin converting enzyme-2 (ACE2) receptor $\cdot$ Convalescent plasma transfer $(\mathrm{CPT})$

\section{Introduction}

Covid-19 is an infectious disease, which has spread globally. The disease is characterized by pneumonia and is an acute respiratory disease. It is caused by Severe Acute Respiratory Syndrome Corona Virus-2 (SARS-CoV-2). The reason it has turned into a pandemic is due to its transmission from infected individuals without symptoms. This infectious disease is the first time reported in Wuhan city, China, in December 2019, occurred due to droplet transmission of SARS-CoV-2 [1]. According to WHO, around 255 million people have been infected with this virus so far, and more than 5 million died globally, in which most of the people were either old or had other underlying complications [2].

Rishi Kumar Jaiswal

rishijai24@gmail.com

1 Department of Pediatrics, Division of Infectious Disease, School of Medicine, Emory University, Atlanta, GA 30322, USA

2 Department of Cancer Biology, Cardinal Bernardin Cancer Center, Loyola University Chicago Stritch School of Medicine, Maywood, IL 60153, USA
Almost every individual has faced direct and indirect loss due to this pandemic, and it needs to be resolved.

It is the third human coronavirus which appeared in the twenty-first century, and the other two are severe acute respiratory syndrome (SARS-CoV-1) and Middle East respiratory syndrome coronaviruses (MERS-CoV), which emerged in 2002 and 2013, respectively. The mortality rate of the last two viruses was high, while they have low transmissibility and infectivity. Different molecular interactions, including receptor interaction, are involved, which determine the host range of a virus [3, 4]. SARS-CoV-2 is an enveloped virus that contains a positive-sense single-stranded RNA. The natural reservoir of this virus is a bat, and then there is a possibility of some amplifying host, which transferred this virus to humans, the final most reservoir [5]. SARSCoV-2 is homologous to SARS-CoV-1 and uses the same mechanism to enter into human lung cells. Both belong to the beta coronavirus group. They both recognize Angiotensin converting enzyme-2 (ACE2) receptor for entering into lung cells, but SARS-CoV-2 has a higher mortality rate. It has around $96 \%$ sequence similarity at the-whole genome level with bat SARS (RaTG13) so considered as bat origin [6]. SARS-CoV-2 uses its envelope spike protein to enter the host cells by interacting with host ACE2 receptor of type II 
alveolar cell of the lung, and the DC-SIGN receptor on the respiratory dendritic cell (DC) and associated endothelial cells $[7,8]$. The name coronavirus was given on the basis of the presence of around 1200 aa long S-protein, which gives a crown-like shape to the coronavirus and comes into class-1 viral fusion proteins [9-11]. The spike protein of SARS-CoV-2 is divided into N-terminal S1-ectodomain and C-terminal S2- membrane-anchored domain by cellular proteases such as cathepsin $\mathrm{L}$, which cleaves the $\mathrm{S}$ glycoprotein at $\mathrm{S} 1 / \mathrm{S} 2$ junction and as well as at $\mathrm{S} 2$ site positioned downstream of S1/S2 proteolytic cleavage [9, 12, 13]. S1 RBD of SARS-CoV-2 is mainly responsible for virus entry and has a higher affinity for ACE2 receptors than SARS CoV spike protein [14]. The S2 domain is accountable for cell membrane fusion and contains an internal fusion peptide, a putative fusion peptide region, a transmembrane domain, and two heptad-repeat domains $[9,12]$. The exact molecular mechanism of SARS-CoV-2 entry into human cells is unknown, but Lu et al. observed that it might be through internal fusion protein and putative fusion protein [10]. The SARS-CoV-2 and SARS-CoV S1 domain share approximately 50 amino acids similarity. Interestingly, Gln493 and Asn501 are the key residues of the SARS-CoV-2 RBD, which are responsible for the binding to the ACE2 receptor and hence further support the idea that SARS-CoV-2 has developed capacity for a person-to-person transmission [12]. The species specificity does not only depend on receptor recognition, but it also depends on its capacity to neutralize innate immune response [15]. However, it is not very well known how SARS-CoV-2 counteracts innate immune response. There is no specific antiviral treatment for SARS$\mathrm{CoV}-2$ treatment and hence social distancing, oxygen therapy, antibiotic treatment for bacterial infection, and fluid management are suggested [16].

While the SARS-CoV-2 virus contains many structural proteins such as spike protein, nucleocapsid protein and core protein, the spike protein is the most immunogenic one and thus vaccination strategy is extensively utilizing spike protein as a candidate for administration. It depends solely on the quantity and quality of neutralization antibodies made in individuals either naturally by their immune system or by administering vaccines. Moreover, in convalescent plasma samples from those who recovered from SARS-CoV-2 infection have a large amount of RBD-specific neutralizing antibodies [17]. So far almost every country is trying to develop a vaccine for SARS-CoV-2and they are in different phases from pre-clinical to human approval stage. In USA there are so far 3 vaccines such as Pfizer BioNTech, Moderna and Johnson and Johnson are approved by Food and drug administration (FDA) for use. Success of vaccine is dependent on durability and stability of neutralization antibody titers. Besides the vaccination, FDA also approved emergency use of plasma therapy which is solely based on transfer of plasma neutralizing antibodies from convalescent patients to newly infected one. This mode of transfer is called passive immunization. The success of plasma therapy varies from person to person as it depends on time of plasma therapy, quality, and quantity of transferred antibodies. Despite the variable response, plasma therapy is still widely used across the world.

Additionally, neutralizing antibodies can also be used in diagnostic tests. As it is based on ELISA using blood so require less technical expertise and can be durable in a large population especially a preliminary test to analyze the seroconversion rate of that population. In this review we are highlighting the importance of neutralizing antibodies. We address many questions such as what are different isotypes of neutralizing antibodies and the cells which have role in production of these antibodies. How these antibodies are useful in plasma therapy and diagnostic serological test. Furthermore, we also discussed the status of neutralization potential in the era of new emerging variants.

\section{New avenue for SARS-CoV-2 treatment using monoclonal antibody}

Antibodies provide a new hope to treat Covid-19 patients because of their specific binding to viral particles and further have neutralization capacity so helping in clearance and/or reducing the viral load in body. So far, there are several monoclonal antibodies in various development stages ranging from preclinical to clinical one as shown in Table 1. Antibodies developed by natural infection in convalescent plasma have variable efficacy and data are not consistent. FDA had approved emergency use authorization (EUA) for convalescent sera in August 2020. For commercial purposes, development of monoclonal antibodies is either developed in humanized mice or purified from convalescent patients or via cell culture techniques as shown in Fig. 1. Monoclonal neutralizing antibodies which have been approved so far for therapeutic intervention include REGN-COV-2 which is IgG1 monoclonal antibody and is a combination of Casirivimab and imdevimab similarly Bamlanivimab or a combination of Bamlanivimab and etesevimab also potential neutralizing antibodies. These antibodies bind to spike RBD region and neutralize SARS-CoV-2 virus effectively [18]. There are various methods/approaches utilized to prepare neutralizing monoclonal antibodies which include: Single cell sort for memory B cells and utilization of next generation high throughput sequencing technique, flow cytometric sorting of antigen specific RBD or spike protein followed by cloning of Ig encoded genes from single B cells, phage display libraries utilized SARS-CoV-2 RBD/ SARS CoV-1 /MERS CoV S proteins, hybridoma culture technique or 
Table 1 The list of monoclonal neutralizing antibodies and their detailed descriptions are enlisted [20] ( source:https://www.antibodysociety.org/ covid-19-biologics-tracker/)

\begin{tabular}{|c|c|c|}
\hline Monoclonal antibody & Phase trial & Company name \\
\hline $\begin{array}{l}\text { REGN10987 and REGN10933 Humanized and human mAb } \\
\text { cocktail [22] or Casirivimab and imdevimab combination }\end{array}$ & Clinical & Regeneron Pharmaceuticals, Inc \\
\hline $\begin{array}{l}\text { LY-CoV555 [23] } \\
\text { Or combination of LY-CoV555 and LY-CoV016 or } \\
\text { LY3819253 }\end{array}$ & Clinical & Eli Lilly and company or AbCellera \\
\hline VIR-7831/GSK4182136 & Clinical & Vir Biotechnology, Inc. and GlaxoSmithKline plc \\
\hline CT P59 & $\begin{array}{l}\text { Conditional } \\
\text { approval in } \\
\text { South Korea }\end{array}$ & Celltrion company \\
\hline $\begin{array}{l}\text { AZD7442 } \\
(\text { AZD8895 + AZD1061) }\end{array}$ & Phase 3 & Astra Zeneca \\
\hline $\begin{array}{l}\text { JS016 } \\
\text { Human mAb [24] }\end{array}$ & Phase 2 & Junshi Biosciences \\
\hline TY027 & Phase -3 & Tychan Pte. Ltd. Singapore \\
\hline BRII-96, BRII-98 & Phase -3 & Brii Biosciences \\
\hline SCTA01 & Phase $2 / 3$ & Sinocelltech Ltd \\
\hline ADM03820 & & Ology Bioservices \\
\hline BI 767551 & Clinical & $\begin{array}{l}\text { Boehringer Ingelheim, Cologne University Hospital (UKK), } \\
\text { University of Marburg (UMR), and the German Center for } \\
\text { Infection Research (DZIF }\end{array}$ \\
\hline COR-101 & Phase $1 / 2$ & CORAT therapeutics \\
\hline ADG20 & Phase $2 / 3$ & \\
\hline MW33 & $\begin{array}{l}\text { Pivotal } \\
\text { Phase } 2\end{array}$ & Mabwell (Shanghai) Bioscience Co., Ltd \\
\hline JS016, LY3832479, LY-CoV016 & Phase 2 & Junshi Biosciences / Eli Lilly and Company \\
\hline DXP593 & Phase 2 & Beigene \\
\hline COVI-AMG (STI-2020) & Phase 2 & Sorrento Therapeutics, Inc \\
\hline BI 767551, DZIF-10c & Phase $2 / 3$ & U. Cologne / Boehringer Ingelheim \\
\hline VIR-7832 & Phase $1 / 2$ & Vir Biotechnol \\
\hline HLX70 & Phase 1 pending & Hengenix Biotech Inc \\
\hline DXP604 & Phase 1 & Beigene \\
\hline ADM03820 & Phase 1 & Ology Bioservices \\
\hline HFB30132A & Phase 1 & HiFiBiO Therapeutics \\
\hline ABBV-47D11 & Phase 1 & AbbVie \\
\hline $\begin{array}{l}\text { C144-LS and } \\
\text { C-135-LS }\end{array}$ & Phase 1 & Bristol-Myers Squibb, Rockefeller University \\
\hline LY-CovMab & Phase 1 & Luye Pharma Group Ltd \\
\hline JMB2002 & Phase 1 & Jemincare Group \\
\hline LY-CoV1404, LY3853113 & Phase 1 & AbCellera / Eli Lilly and Company \\
\hline
\end{tabular}

utilization of EBV immortalized memory B cells etc. [19]. High cost involved in large scale production of monoclonal antibodies and their testing is a limiting factor for mass scale usage as a therapeutic agent.

The list of monoclonal neutralizing antibodies and their detailed descriptions are enlisted in Table 1 [20] (source:https://www.antibodysociety.org/covid-19-biolo gics-tracker/). Summary of monoclonal antibodies which are tested for their neutralization potential in different research labs with their potential mode of action are listed in Table 2 [21].

\section{Different isotype of neutralizing antibodies and their role during Covid-19 infection}

In the course of any infection our immune system produces two types of antibodies that is unswitched and switched isotype. In acute Covid-19 infection, neutralizing antibodies 
Fig. 1 A schematic of development of monoclonal antibody. Different phases of antibody generation start from (1) generation of antibody in the lab (2) Screening of antibody and (3) Commercial manufacturing, clinical trials and approval, and distribution for therapeutic use

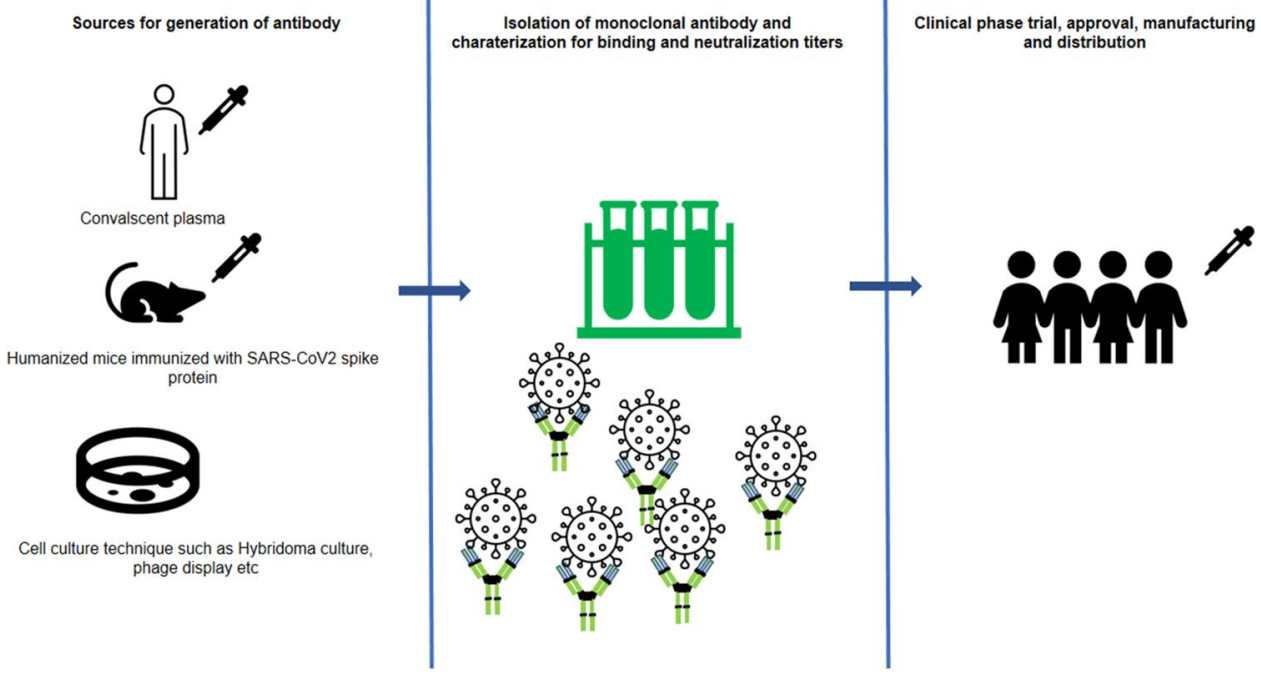

are dominated mainly by switched type antibodies such as $\mathrm{IgG}$ and $\operatorname{IgA}$ and less by unswitched IgM type. An early report revealed the role of spike protein where they discovered that RBD specific IgG neutralizing antibodies could prevent cell-to-cell fusion between virus spike protein and ACE2 receptor and thus stop the virus entry to lung cells and further transmission of the virus as shown in Fig. 2 [25]. Additionally, when analyzing the immune repertoire from convalescent patient plasma cells by single-cell sequencing, the authors observed clonal expansion of certain IgG repertoire. Many of these expanded clones are SARS-CoV-2 antigen-specific, with high affinity for RBD specific having neutralization potential [26]. Acute Covid-19 patients have more RBD specific IgG antibodies compared to IgM and IgA. Among IgG isotype, IgG1 and IgG3 are more prevalent in acute patient plasma samples post one week of symptom development. These RBD specific IgG antibodies have strong neutralization potential during acute SARS-CoV-2 early infection, day 7 post PCR positive test. These reports show the serological importance of Covid-19 during acute infection in diagnosis [27]. Marot $\mathrm{S}$ et al. report came from healthcare workers analysis, which suggests that the rate of decline of RBD specific neutralizing antibodies decline rate is different among $\operatorname{IgM}, \operatorname{IgG}$, and $\operatorname{IgA}$ isotypes. While $\operatorname{IgG}$ and $\mathrm{IgA}$ titers are stable or reduced slightly from day 21 to 3 months during mild symptom development, IgM antibody level and its neutralization titers decline rapidly from day 21 to 2 months and continue further after 3 months. These data reflect lower persistence of IgM neutralization antibodies once developed compared to $\operatorname{IgG}$ and $\operatorname{IgA}$ [28]. Sterlin et al. have reported the importance of $\operatorname{IgA}$ antibodies in acute SARS-CoV-2 patients. IgA can be detected in serum, saliva as well as bronchoalveolar lavage fluid during initial time of infection and it has neutralization potential as well. IgA plasmablasts undergo peripheral expansion and homing as measured by CCR10 positivity (homing marker from lung cells to mucosal site) plasmablast and memory cells soon after the onset of symptoms and reach peak at 3 weeks towards mucosal site is seen. IgA antibody titers start declining after 3-4 weeks of symptom onset while IgG remains in plateau and detectable in serum [29]. Wajnberg A et al. demonstrated that $\operatorname{IgG}$ is the major antibody with higher neutralization titers and relative stability in Covid19 recovered patients. Their data suggested that RBD IgG antibodies as a suitable candidate for plasma therapy [30]. The kinetics of neutralization antibody titers as measured by Plaque reduction neutralization titers $\left(\mathrm{PRNT}_{50}\right)$ decline are also dependent on the severity of symptoms. Severe ill patients retain antibodies longer than mild and then shorter in the asymptomatic patients as shown in Supplementary Fig. 1 [28]. Moreover, Long QX et al. demonstrated the seroconversion of different antibodies. They found that virus-specific IgG and IgM neutralizing antibodies occur simultaneously and were detected in serum starting from the first week of infection and reach a peak approximately in three weeks in all tested Covid-19 patients. Interestingly, both the antibodies are higher in the severely ill patients compared to the non-severe group. They observed simultaneous seroconversion for both $\operatorname{IgG}$ and IgM in almost all patients tested, and median seroconversion reached day 13 of symptom onset. This report also highlights the importance of serological test to detect $\operatorname{IgG}$ and $\operatorname{IgM}$ as a diagnostic test for Covid-19 patient who is negative for RT-PCR test at a specific window of time [31]. So, in summary these reports highlight that for passive immunization antibodies transfer IgG antibodies post day 7-21 infection are suitable to transfer into patients who have Covid-19 at early stage that is 3-7 days. Meta-analysis studies show that convalescent 


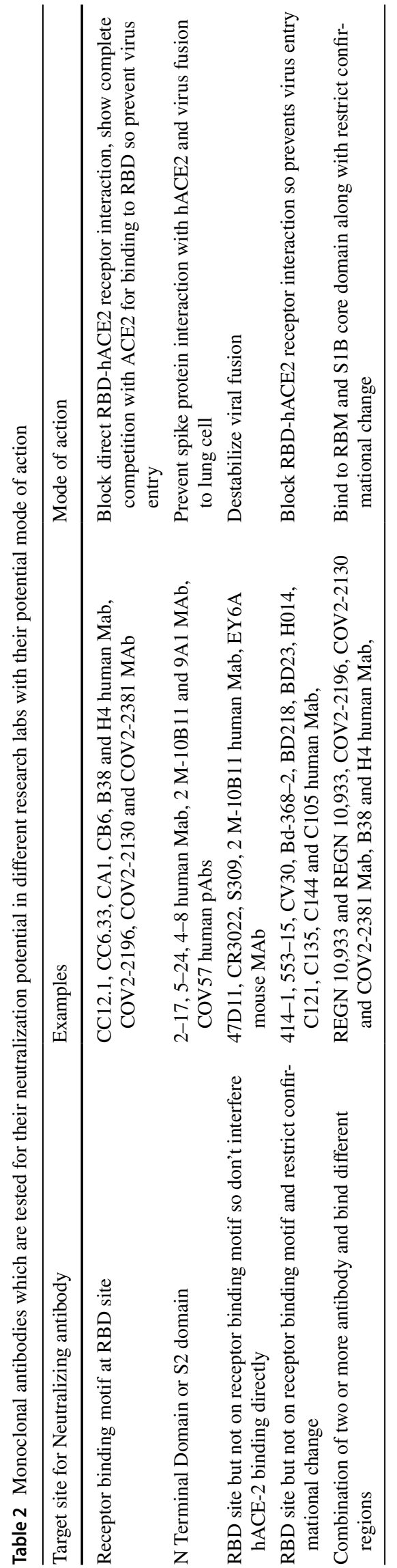

plasma transfer (CPT) to hospitalized severely ill patients leads to less mortality rate, and it is most effective when administered within 3 days of the onset of symptoms. This treatment is safe and can be combined with other standard treatments. The limitation of these studies are absence of controls and randomized clinical trials [32,33]. Maeda et al. highlighted about enhance neutralization potential after receiving CPT. They reported around $60 \%$ patients showed significant increased neutralization activity once treated with CPT, but half of the patient lost neutralization potential in a one-month time. They also conclude that IgG CPT neutralizing activity remain inconsistent and varies from person to person and does not positively correlated with binding antibodies specific for SARS-CoV-2 S1 [34]

\section{B cells response during Covid-19 infection}

Neutralizing antibodies are produced by B cells. B cells terminally differentiated into plasma cells and secrete antibodies into serum as shown in Supplementary Fig. 2. There are two types of B cell response: the extrafollicular B cell response, and another is the follicular response that led to the germinal center (GC) reaction. IgM neutralizing antibodies are mainly produced during extrafollicular B cell response, while switched ones such as IgG and IgA are generated during GC reaction, which are of higher affinity [35]. Successful vaccination is dependent on the long-term production of neutralizing antibodies by formation and persistence of either long-lived plasma cells or memory cells which are outcomes of GC reaction from a secondary lymphoid organ such as the spleen and lymph nodes as shown in Supplementary Fig. 2. Cross sectional study in acute SARS-CoV-2 infection patient suggested that total B cell frequency as well as plasmablast frequency increase in blood and peak at around 2 weeks post the onset of symptoms and then start to decline. While analyzing RBD specific switched memory $\mathrm{B}$ cells, this also showed a similar pattern to antibodies in terms of isotype. RBD specific IgG memory B cells are dominated followed by IgA and then IgM type [36].

In SARS-CoV-2 acute severe diseases, there is a reduction in GC rection thus diminished formation of long-lived plasma cells and memory B cells. Therefore, high affinity and class switched neutralizing antibody production are lowered in this situation. Moreover, this report, has shown a reduction in $\mathrm{Bcl} 6+\mathrm{B}$ cells, a marker for $\mathrm{GC} \mathrm{B}$ cells and $\mathrm{T}$ follicular helper cells in postmortem spleen and thoracic lymph node tissue. They also showed aberrantly activated B cell population in peripheral blood and TNF alpha expression. This also explains short lived neutralizing antibody production in the SARS-CoV-2 acute disease scenario and further suggests difficulties in getting herd immunity by natural infection [37, 38]. Woodruff MC et al. also confirmed 
Fig. 2 Mechanism of action of neutralizing antibody: Once neutralizing antibody interacts with spike or RBD site, it prevents the entry by blocking Spike protein to ACE2 interaction. Another way is to prevent the fusion of the virus envelope to the cellular endosome

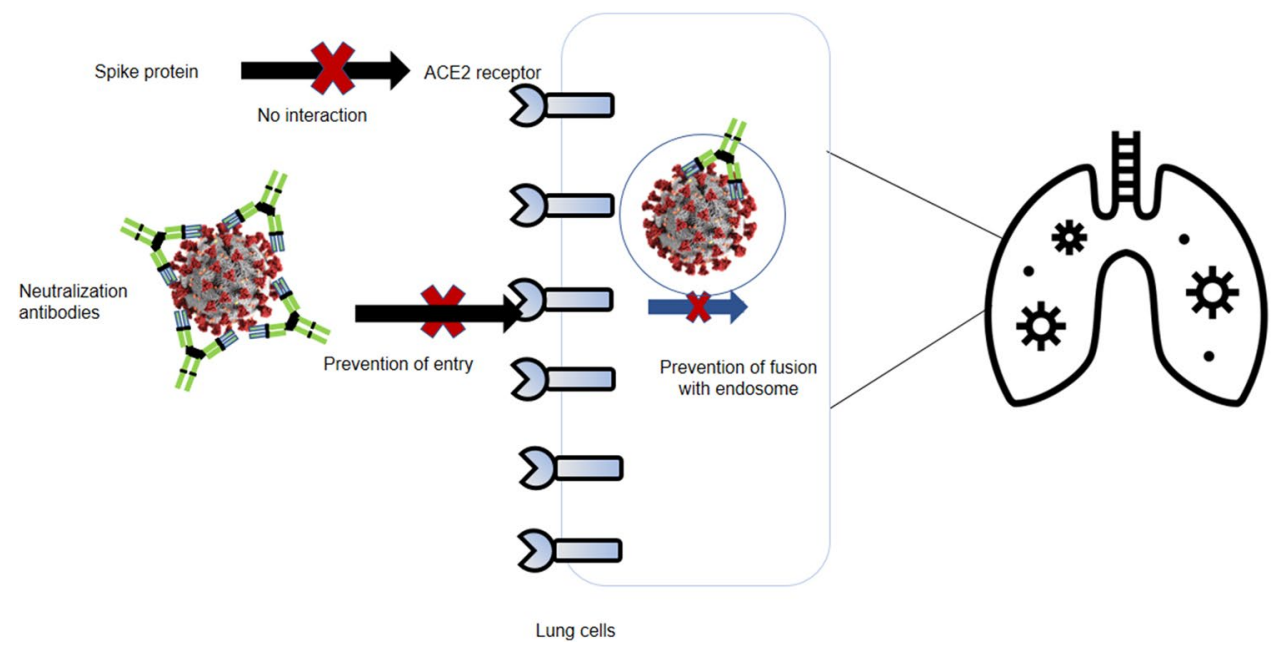

a similar finding that explained the differential outcome of antibody response for asymptomatic to severely ill patients. They showed that in the severely ill patients, extrafollicular B cell response is higher and also $\operatorname{IgM}$ and switched antibodies while the asymptomatic patient has higher follicular B cell response, GC reaction and memory response. Furthermore, they also revealed that severely ill patient showed high autoimmune pathology like Systemic lupus erythematosus (SLE) and had a positive correlation with autoimmunity. In severely ill patients blood sample, when they did phenotyping for the effector cells, they observed that activated naïve population expanded and differentiated into a unique double negative (DN) effector population. The extrafollicular response pathway in severely ill patients has a positive correlation with IL6, C-reactive protein, IP10 level in serum which is identified as a biomarker of Covid19 disease. There is a robust expansion of CD138+ mature plasma cells in severely ill patients that leads to production of a large number of neutralizing antibodies compared to both asymptomatic and healthy patients, but they are the extrafollicular type [39].

For long term antibody production during reinfection, memory cells play an important role. Deng W et al. reported in rhesus macaque that suggested protection against reinfection and generation of long-term immunity. This report compared the primary challenge infection case with the challenge-rechallenge (i.e. reinfection) point in the rhesus macaque non-primate model. They found that reinfection post 28-day after recovery from primary infection showed higher IgG neutralizing antibodies against virus spike protein and have no viral load detection. This also indicates that if we give two doses in a 28-day interval of virus vaccine it offered better protection as higher production of neutralizing antibodies. Though a long-term challenge to see memory response remains unexplored to observe quantitative and qualitative long term immune response [40]. The chance of reinfection also depends on antibody level made from prior infection. Once a person recovers from acute SARS-CoV-2 infection. They are more likely to get reinfected if they remain seronegative compared to a seropositive person [41]. Among memory B cells analyzed 6 months post infection, $\mathrm{IgG}$ memory B cells are predominant followed by IgA memory and sustained post 6 months of infection. In contrast, IgM memory B cells are short lived one, so they start to decline gradually [42]. Antibodies generated from memory B cells after 6 months of infection showed an example of continued evolution in terms of increased neutralization potential and breadth in their repertoire, increased somatic hypermutation which indicate antigen persistence for longer duration [43].

The drawback in most of human studies so far on Covid-19 project is that they are largely based on blood sample study. So, trafficking of memory cells and long-lived plasma cells in bone marrow is still limited. Similarly for IgA study at mucosal site is still needs to be carry out in extensive manner. One recent study done in human bone marrow aspirates in mild Covid-19 infected convalescent patient shows persistence of long-lived plasma cells up to 6-8 months. They showed in longitudinal study that decay in anti-S antibody titers are rapid for 1 months then gradual decline from 1 to 4 months and very slow decrease in mean titers till 11 months. Thus, persistence of IgG antibody till 11 months post symptom onset in some convalescent patient sera. When analyzing S-binding memory B cells in blood, it is detected as soon as one month post symptom onset and remain detectable at least for 7 month [44]. This study highlighted the long-term immunity for spike protein in mild infected patients. So, in nutshell during infection, first viral loads reach at their peak level, then antibody start to develop to fight against virus and neutralize them. Later, IgG antibody predominates and provide long term immunity as shown in Supplementary Fig. 3. 


\section{Serological test}

The Serological tests are meant to detect antibody levels against the SARS-CoV-2 virus. It is different from the diagnostic RT-PCR test in which there is the detection of genetic material. Serological test showed a history of whether an individual was infected with Covid-19 diseases in the past. In contrast, a diagnostic test is more suitable for an individual who is currently infected. Serological tests can be performed as early as 6 days and reach a peak on 14 to 30 days post the onset of symptom while SARS-CoV-2 RNA can be detected as early as $2-3$ days post symptom onset peak at day 5 and remain detectable from 25 to 50 days. Serological tests are not recommended to the population with low disease prevalence, infectious patients at an early stage or asymptomatic or pseudo symptomatic patients, and healthcare professionals at higher risk of Covid-19 infection [45, 46]. Comparison between serological test to diagnostic test is summarized in Supplementary Table 1.

Serological tests only give the information of the quantity of spike and/or RBD specific antibody in serum and is done by ELISA as shown in Supplementary Fig. 4. But the functionality of these antibodies is determined by neutralization assay. There are mainly two type of neutralization assay, one is based on live virus neutralization titers and second on pseudo type virus neutralization in which spike is conjugated to another virus such as HIV or VSV. Live virus neutralization shows more accurate results but using pseudo type virus gives the flexibility of working in BSL2 facility instead of BSL3 for live virus culture. Neutralization titers detection technique using patient serum/plasma to detect SARS-CoV-2 antibodies are listed below in Supplementary Table-2. When $\mathrm{PRNT}_{50}$ is quantified, the estimated time duration to drop 1:10 detection limit antibody titers in various patient, depends on disease severity. As reported, it took approximately 372, 416 and 133 days for severe, mild and asymptomatic patients respectively [47].

\section{Mutants and neutralization potential}

Few vaccines which are currently in human trial are as Pfizer BioNTech or BNT162b2, Moderna or mRNA-1273, Johnson and Johnson or Ad26.COV2.S, Covaxin or BBV152, Astrazeneca or AZD1222, Sputnik V and Gamaleya etc. Emerging new variant cause a serious concern against vaccine use for long term and its efficacy reliability. SARS-CoV-2 is a single stranded RNA virus, and the mutation rate is higher in viruses than any other pathogen such as bacteria or fungi. Mutation in spike protein causes decline in the neutralization potential of antibodies and the vaccination efficacy of an individual. The list of few variants is reported as given below in Supplementary Table 3 [52-54]:

Neutralization titers $\left(\mathrm{FRNT}_{50}\right)$ were compared for different variants of SARS-CoV-2, such as UK variant (B.1.1.7) and USA Atlanta variant (B.1 lineage), USA San Diego variant (N501Y) along with the first reported original china variant (A.1 lineage). Their neutralization potential was found to be comparable in acute and convalescent serum sample. Individual received mRNA-1273 vaccination show slight reduction in neutralization antibody titers against SARSCoV-2 variant compared to original A.1 lineage [55]. Similarly in another report from the same group compared receptor binding and neutralization titers between USA Atlanta variant B.1 lineage and South African (B.1.351 lineage) in acute, convalescent and post second dose mRNA 1273 vaccinated serum sample. They observed a 3-fourfold reduction in both binding to receptor binding domain as well as neutralization titers against B.1.351 lineage compared to B.1 lineage. This shows one of the concerns for reducing efficacy for SARS-Cov2 vaccination as shown in Supplementary Fig. 5. It also highlighted a raising concern of every year vaccination as emerging new variants with more transmissible rate, viral fitness and the higher fatality rate can cause failure in existing vaccination as neutralization antibodies will no longer bind to spike protein and prevent entry to lung cells [56]. Additionally, Planas D. et al. have reported partial reduction in neutralization potential against SARSCoV-2 variants developed either by natural infection or post Pfizer vaccination. In this report that reduction is more towards B.1.351 than B.1.1.7 compared to B1 prototype variant (D614G). Yadav et al. have reported that individuals administered Covaxin and convalescent sera from recovered Covid-19 patients both are able to neutralize efficiently for the variant B.1.617 (Indian variant) and B.1.17 (UK variant) when compared with B1 prototype variant (D614G) against which Covaxin is developed [54]. Invitro culture study shows moderately diminished neutralization antibody titers against SARS-CoV-2, in various tested SARS-CoV-2 variants that have variation in spike sequences generated by deletions or substitutions, when treated with monoclonal antibody or convalescent sera. This report indicated development of resistance for monoclonal antibodies [57, 58]. Results from longitudinal study have shown that after vaccination, naïve individuals showed enhanced antibody titers after second dose of mRNA vaccine while recovered patient from natural Covid-19 infection, first dose gave accelerated antibody titers against B.1.351 SARS-CoV-2 variant. This paper also showed that in naïve individuals antigen specific memory cell formation is primarily of the IgM isotype after the first dose of vaccination and IgG isotype after second dose, in contrast to that in recovered individual where it is largely IgG memory after first dose of mRNA vaccine [59]. In nutshell, as SARS-CoV-2 is now spread globally so any 
new emerging variant which gave virus more fitness, transmission ability and less susceptible to existing vaccine is the biggest challenge to complete eradicate Covid-19 disease. Every country is now actively vigilant for emerging new wave of this disease due to new mutant.

\section{Future perspective}

Lack of long-term study, small cohort size and emerging variants cause a serious setback regarding the efficacy of vaccination. Long term memory B cell response and breadth of repertoire are still needed to study extensively. Production of neutralizing antibodies requires not only $B$ cells but also $T$ cells and innate cells. The range of symptoms and variation in antibody response has left the scientific community puzzled. How herd immunity and pre-existing immunity impact the quality and quantity of neutralization titers remain to be explored. Zoonotic origin of this disease gave a speculation of pre-existing immunity as reported by $\mathrm{Ng}$ et al., in which they found S2 subunit specific IgG antibodies in uninfected patients that have neutralization potential. This also reflect cross reactive nature of antibodies. There is a differential expression of these antibodies in children and adolescent one [60]. Antibody titers also showed correlation with age. While seroconversion rate is similar between pediatric vs adult patient, IgG antibody titers are negatively correlated with age in pediatric patient and moderately positive with adult patients [61]. This highlights that a differential course of vaccination might be needed in children compared to adult. Development of immune escape mutations in SARS-CoV-2 and resistant to vaccine, drug as well as neutralizing monoclonal antibodies are the biggest challenges in future eradication of the disease.

Supplementary Information The online version contains supplementary material available at https://doi.org/10.1007/s11033-021-07020-6.

Author contributions S.G and R.K.J hypothesize the idea, and they both wrote the manuscript.

Funding The author(s) received no financial support for the authorship, and/or publication of this article.

\section{Declarations}

Conflict of interest The authors declare no potential competing interest.

Ethical approval No animal has been used in this study.

Informed consent All authors are agree to publish this manuscript in your valuable journal.

\section{References}

1. Lu H, Stratton CW, Tang YW (2020) Outbreak of pneumonia of unknown etiology in Wuhan, China: the mystery and the miracle. J Med Virol 92(4):401-402. https://doi.org/10.1056/NEJMc21003 62

2. Chen N, Zhou M, Dong X, Qu J, Gong F, Han Y, Zhang L (2020) Epidemiological and clinical characteristics of 99 cases of 2019 novel coronavirus pneumonia in Wuhan, China: a descriptive study. The Lancet 395(10223):507-513. https://doi. org/10.1016/S0140-6736(20)30211-7

3. de Wit E, van Doremalen N, Falzarano D, Munster VJ (2016) SARS and MERS: recent insights into emerging coronaviruses. Nat Rev Microbiol 14(8):523-534. https://doi.org/10.1038/ nrmicro.2016.81

4. Wang L, Wang Y, Ye D, Liu Q (2020) Review of the 2019 novel coronavirus (SARS-CoV-2) based on current evidence. Int J Antimicrob Agents 55(6):105948. https://doi.org/10.1016/j.ijant imicag.2020.105948

5. Guan Y, Zheng BJ, He YQ, Liu XL, Zhuang ZX, Cheung CL, Luo SW et al (2003) Isolation and characterization of viruses related to the SARS coronavirus from animals in southern China. Science 302(5643):276-278. https://doi.org/10.1126/ science. 1087139

6. Zhou P, Yang X-L, Wang X-G, Ben Hu, Zhang L, Zhang W, Si $\mathrm{H}-\mathrm{R}$ et al (2020) A pneumonia outbreak associated with a new coronavirus of probable bat origin. Nature 579(7798):270-273. https://doi.org/10.1038/s41586-020-2012-7

7. Wan Y, Shang J, Graham R, Baric RS, Li F (2020) Receptor recognition by the novel coronavirus from Wuhan: an analysis based on decade-long structural studies of SARS coronavirus. J Virol 94(7):e00127-e120. https://doi.org/10.1128/jvi.00127-20

8. Brufsky A, Lotze MT (2020) DC/L-SIGNs of hope in the COVID19 pandemic. J Med Virol 92(9):1396-1398. https://doi.org/10. 1002/jmv. 25980

9. Coutard B, Valle C, de Lamballerie X, Canard B, Seidah NG, Decroly E (2020) The spike glycoprotein of the new coronavirus 2019-nCoV contains a furin-like cleavage site absent in CoV of the same clade. Antiviral Res 176:104742. https://doi.org/10. 1016/j.antiviral.2020.104742

10. Lu G, Wang Q, Gao GF (2015) Bat-to-human: spike features determining "host jump" of coronaviruses SARS-CoV, MERS$\mathrm{CoV}$, and beyond. Trends Microbiol 23(8):468-478. https://doi. org/10.1016/j.tim.2015.06.003

11. Millet JK, Whittaker GR (2014) Host cell entry of Middle East respiratory syndrome coronavirus after two-step, furin-mediated activation of the spike protein. Proc Natl Acad Sci 111(42):1521415219. https://doi.org/10.1073/pnas. 1407087111

12. Lu Roujian, Zhao Xiang, Li Juan, Niu Peihua, Yang Bo, Honglong Wu, Wang Wenling et al (2020) Genomic characterisation and epidemiology of 2019 novel coronavirus: implications for virus origins and receptor binding. Lancet 395(10224):565-74. https:// doi.org/10.1016/S0140-6736(20)30251-8

13. Li W, Moore MJ, Vasilieva N, Sui J, Wong SK, Berne MA, Somasundaran M et al (2020) Genomic characterisation and epidemiology of 2019 novel coronavirus: implications for virus origins and receptor binding. Lancet 395(10224):565-574. https:// doi.org/10.1038/nature02145

14. Wrapp D, Wang N, Corbett KS, Goldsmith JA, Hsieh C-L, Abiona O, Graham BS, McLellan JS (2020) Cryo-EM structure of the 2019-nCoV spike in the prefusion conformation. Science 367(6483):1260-1263. https://doi.org/10.1126/science.abb2507

15. Huang C, Wang Y, Li X, Ren L, Zhao J, Yi Hu, Zhang Li et al (2020) Clinical features of patients infected with 2019 novel 
coronavirus in Wuhan, China. Lancet 395(10223):497-506. https://doi.org/10.1016/S0140-6736(20)30183-5

16. Habibzadeh P, Stoneman EK (2020) The novel coronavirus: A bird's eye view. Int J Occup Environ Med 11(2):65-71. https:// doi.org/10.15171/ijoem.2020.1921

17. Hoffmann M, Kleine-Weber H, Schroeder S, Kruger N, Herrler T, Erichsen S, Schiergens TS et al (2020) SARS-CoV-2 cell entry depends on ACE2 and TMPRSS2 and is blocked by a clinically proven protease inhibitor. Cell 181(2):271-280 e278. https://doi. org/10.1016/j.cell.2020.02.052

18. Taylor PC, Adams AC, Hufford MM, de la Torre I, Winthrop K, Gottlieb RL (2021) Neutralizing monoclonal antibodies for treatment of COVID-19. Nat Rev Immunol. https://doi.org/10.1038/ s41577-021-00542-x

19. Jaworski JP (2021) Neutralizing monoclonal antibodies for COVID-19 treatment and prevention. Biomed J 44(1):7-17. https://doi.org/10.1016/j.bj.2020.11.011

20. DeFrancesco L (2020) COVID-19 antibodies on trial. Nat Biotechnol 38(11):1242-1252. https://doi.org/10.1038/ s41587-020-0732-8

21. Gavor E, Choong YK, Er SY, Sivaraman H, Sivaraman J (2020) Structural Basis of SARS-CoV-2 and SARS-CoV Antibody Interactions. Trends Immunol 41(11):1006-1022. https://doi.org/10. 1016/j.it.2020.09.004

22. Hansen J, Baum A, Pascal KE, Russo V, Giordano S, Wloga E, Fulton BO et al (2020) Studies in humanized mice and convalescent humans yield a SARS-CoV-2 antibody cocktail. Science 369(6506):1010-1014. https://doi.org/10.1126/science.abd0827

23. Chen P, Nirula A, Heller B, Gottlieb RL, Boscia J, Morris J et al (2020) SARS-CoV-2 neutralizing antibody LY-CoV555 in outpatients with Covid-19. N Engl J Med 384(3):229-237. https://doi. org/10.1056/NEJMoa2029849

24. Shi R, Shan C, Duan X, Chen Z, Liu P, Song J et al (2020) A human neutralizing antibody targets the receptor-binding site of SARS-CoV-2. Nature 584(7819):120-124. https://doi.org/10. 1038/s41586-020-2381-y

25. Wang L, Zhao J, Nguyen LNT, Adkins JL, Schank M, Khanal S et al (2021) Blockade of SARS-CoV-2 spike protein-mediated cell-cell fusion using COVID-19 convalescent plasma. Sci Rep 11(1):5558. https://doi.org/10.1038/s41598-021-84840-3

26. Ehling, R. A., Weber, C. R., Mason, D. M., Friedensohn, S., Wagner, B., Bieberich, F., et al. (2021). Single-cell sequencing of plasma cells from COVID-19 patients reveals highly expanded clonal lineages produce specific and neutralizing antibodies to SARS-CoV-2. bioRxiv,. Doi:https://doi.org/10.1101/2021.02.12. 430940.

27. Suthar MS, Zimmerman MG, Kauffman RC, Mantus G, Linderman SL, Hudson WH et al (2020) Rapid generation of neutralizing antibody responses in COVID-19 patients. Cell Rep Med 1(3):100040. https://doi.org/10.1016/j.xcrm.2020.100040

28. Marot S, Malet I, Leducq V, Zafilaza K, Sterlin D, Planas D et al (2021) Rapid decline of neutralizing antibodies against SARS-CoV-2 among infected healthcare workers. Nat Commun 12(1):844. https://doi.org/10.1038/s41467-021-21111-9

29. Sterlin D, Mathian A, Miyara M, Mohr A, Anna F, Claër L et al (2021) IgA dominates the early neutralizing antibody response to SARS-CoV-2. Sci Transl Med. https://doi.org/10.1126/scitranslm ed.abd2223

30. Wajnberg A, Amanat F, Firpo A, Altman DR, Bailey MJ et al (2020) Robust neutralizing antibodies to SARS-CoV-2 infection persist for months. Science 370(6521):1227-1230. https://doi.org/ 10.1126/science.abd7728

31. Long QX, Liu BZ, Deng HJ, Wu GC, Deng K, Chen YK et al (2020) Antibody responses to SARS-CoV-2 in patients with COVID-19. Nat Med 26(6):845-848. https://doi.org/10.1038/ s41591-020-0897-1
32. Rajendran K, Krishnasamy N, Rangarajan J, Rathinam J, Natarajan M, Ramachandran A (2020) Convalescent plasma transfusion for the treatment of COVID-19: Systematic review. J Med Virol 92(9):1475-1483. https://doi.org/10.1002/jmv.25961

33. Klassen SA, Senefeld JW, Johnson PW, Carter RE, Wiggins CC, Shoham S et al (2021) The effect of convalescent plasma therapy on mortality among patients with COVID-19: systematic review and meta-analysis. Mayo Clin Proc 96(5):1262-1275. https://doi. org/10.1016/j.mayocp.2021.02.008

34. Maeda K, Higashi-Kuwata N, Kinoshita N, Kutsuna S, Tsuchiya K, Hattori S-I et al (2021) Neutralization of SARS-CoV-2 with IgG from COVID-19-convalescent plasma. Sci Rep 11(1):5563. https://doi.org/10.1038/s41598-021-84733-5

35. Hoffmann M, Kleine-Weber H, Schroeder S, Kruger N, Herrler T, Erichsen S et al (2020) SARS-CoV-2 cell entry depends on ACE2 and TMPRSS2 and is blocked by a clinically proven protease inhibitor. Cell 181(2):271-280 e278. https://doi.org/10. 1016/j.cell.2020.02.052

36. Mantus G, Nyhoff LE, Kauffman RC, Edara VV, Lai L, Floyd K et al (2021) Evaluation of cellular and serological responses to acute SARS-CoV-2 infection demonstrates the functional importance of the receptor-binding domain. J Immunol 206(11):26052613. https://doi.org/10.4049/jimmunol.2001420

37. Kaneko N, Kuo HH, Boucau J, Farmer JR, Allard-Chamard H, Mahajan VS, Piechocka-Trocha A et al (2020) Loss of Bcl-6-expressing T Follicular helper cells and germinal centers in COVID19. Cell 183(1):143-157 e113. https://doi.org/10.1016/j.cell.2020. 08.025

38. Canete PF, Vinuesa CG (2020) COVID-19 makes B cells forget, but T cells remember. Cell 183(1):13-15. https://doi.org/10. 1016/j.cell.2020.09.013

39. Woodruff MC, Ramonell RP, Nguyen DC, Cashman KS, Saini AS, Haddad NS, Ley AM et al (2020) Extrafollicular B cell responses correlate with neutralizing antibodies and morbidity in COVID19. Nat Immunol 21(12):1506-1516. https://doi.org/10.1038/ s41590-020-00814-z

40. Deng W, Bao L, Liu J, Xiao C, Liu J, Xue J, Lv Q et al (2020) Primary exposure to SARS-CoV-2 protects against reinfection in rhesus macaques. Science 369(6505):818-823. https://doi.org/10. 1126/science.abc5343

41. Letizia Andrew G, Ge Yongchao, Vangeti Sindhu, Goforth Carl, Weir Dawn L, Kuzmina Natalia A, Balinsky Corey A et al (2021) SARS-CoV-2 seropositivity and subsequent infection risk in healthy young adults: a prospective cohort study. Lancet Respir Med. https://doi.org/10.1016/S2213-2600(21)00158-2

42. Dan Jennifer M, Jose Mateus Yu, Kato Kathryn M, Hastie Esther Dawen, Yu Caterina E, Faliti Alba Grifoni et al (2021) Immunological memory to SARS-CoV-2 assessed for up to 8 months after infection. Science. https://doi.org/10.1126/science.abf4063

43. Gaebler C, Wang Z, Lorenzi JCC, Muecksch F, Finkin S, Tokuyama M, Cho A et al (2021) Evolution of antibody immunity to SARS-CoV-2. Nature 591(7851):639-644. https://doi.org/10. 1038/s41586-021-03207-w

44. Turner JS, Kim W, Kalaidina E, Goss CW, Rauseo AM, Schmitz AJ, Hansen L et al (2021) SARS-CoV-2 infection induces longlived bone marrow plasma cells in humans. Nature. https://doi. org/10.1038/s41586-021-03647-4

45. West R, Kobokovich A, Connell N, Gronvall GK (2021) COVID19 antibody tests: a valuable public health tool with limited relevance to individuals. Trends Microbiol 29(3):214-223. https:// doi.org/10.1016/j.tim.2020.11.002

46. Peeling RW, Wedderburn CJ, Garcia PJ, Boeras D, Fongwen N, Nkengasong J et al (2020) Serology testing in the COVID-19 pandemic response. Lancet Infect Dis 20(9):e245-e249. https://doi. org/10.1016/S1473-3099(20)30517-X 
47. Lau EHY, Tsang OTY, Hui DSC, Kwan MYW, Chan W-H, Chiu SS, Ko RLW et al (2021) Neutralizing antibody titres in SARSCoV-2 infections. Nat Commun 12(1):63. https://doi.org/10.1038/ s41467-020-20247-4

48. Vanderheiden A, Edara VV, Floyd K, Kauffman RC, Mantus G, Anderson E, Rouphael N et al (2020) Development of a rapid focus reduction neutralization test assay for measuring SARSCoV-2 neutralizing antibodies. Curr Protoc Immunol 131(1):e116. https://doi.org/10.1002/cpim.116

49. Schmidt Fabian, Weisblum Yiska, Muecksch Frauke, Hoffmann Hans-Heinrich, Michailidis Eleftherios, Lorenzi Julio C.C., Mendoza Pilar et al (2020) Measuring SARS-CoV-2 neutralizing antibody activity using pseudotyped and chimeric viruses. J Exp Med. https://doi.org/10.1084/jem.20201181

50. Crawford KHD, Eguia R, Dingens AS, Loes AN, Malone KD, Wolf CR, Chu HY et al (2020) Protocol and reagents for pseudotyping lentiviral particles with SARS- CoV-2 spike protein for neutralization assays. Viruses. https://doi.org/10.3390/v12050513

51. Zeng Cong, Evans John P, Pearson Rebecca, Panke Qu, Zheng Yi-Min, Robinson Richard T, Hall-Stoodley Luanne et al (2020) Neutralizing antibody against SARS-CoV-2 spike in COVID-19 patients, health care workers, and convalescent plasma donors. JCI Insight. https://doi.org/10.1172/jci.insight.143213

52. Abdool Karim SS, de Oliveira T (2021) New SARS-CoV-2 variants - clinical, public health, and vaccine implications. N Engl J Med. https://doi.org/10.1056/NEJMc2100362

53. Burki T (2021) Understanding variants of SARS-CoV-2. The Lancet 397(10273):462. https://doi.org/10.1016/S0140-6736(21) 00298-1

54. Yadav, Pragya D., Gajanan N. Sapkal, Priya Abraham, Raches Ella, Gururaj Deshpande, Deepak Y. Patil, Dimpal A Nyayanit, et al. (2021). Neutralization of variant under investigation B.1.617 with sera of BBV152 vaccinees. bioRxiv, Doi:https://doi.org/10. 1101/2021.04.23.441101

55. Edara VV, Hudson WH, Xie X, Ahmed R, Suthar MS (2021) Neutralizing antibodies against SARS-CoV-2 variants after infection and vaccination. JAMA. https://doi.org/10.1001/jama.2021.4388
56. Edara, V. V., C. Norwood, K. Floyd, L. Lai, M. E. Davis-Gardner, W. H. Hudson, G. Mantus, et al. (2021). Reduced binding and neutralization of infection- and vaccine-induced antibodies to the B.1.351 (South African) SARS-CoV-2 variant. bioRxiv. Doi:https://doi.org/10.1101/2021.02.20.432046.

57. Chen RE, Zhang X, Case JB, Winkler ES, Liu Y, VanBlargan LA, Liu J et al (2021) Resistance of SARS-CoV-2 variants to neutralization by monoclonal and serum-derived polyclonal antibodies. Nat Med 27(4):717-726. https://doi.org/10.1038/ s41591-021-01294-w

58. Weisblum Y, Schmidt F, Zhang F, DaSilva J, Poston D, Lorenzi JC et al (2020) Escape from neutralizing antibodies by SARS-CoV-2 spike protein variants. eLife 9:e61312. https://doi.org/10.7554/ eLife.61312

59. Goel RR, Apostolidis SA, Painter MM, Mathew D, Pattekar A, Kuthuru O et al (2021) Distinct antibody and memory B cell responses in SARS-CoV-2 naïve and recovered individuals following mRNA vaccination. Sci Immunol. https://doi.org/10.1126/ sciimmunol.abi6950

60. Ng KW, Faulkner N, Cornish GH, Rosa A, Harvey R, Hussain S et al (2020) Preexisting and de novo humoral immunity to SARSCoV-2 in humans. Science 370(6522):1339-1343. https://doi.org/ 10.1126/science.abe1107

61. Yang HS, Costa V, Racine-Brzostek SE, Acker KP, Yee J, Chen $\mathrm{Z}$ et al (2021) Association of Age With SARS-CoV-2 Antibody Response. JAMA Netw Open 4(3):e214302-e214302. https://doi. org/10.1001/jamanetworkopen.2021.4302

Publisher's Note Springer Nature remains neutral with regard to jurisdictional claims in published maps and institutional affiliations. 